\title{
Prevalência de injúrias dentárias e orofaciais e o conhecimento dos atletas sobre as condutas emergenciais
}

\author{
Prevalence of dental and orofacial injuries and the knowledge of athletes about \\ emergency procedures
}

\begin{abstract}
Kathya Aparecida Palatim Semencio, ${ }^{1}$ Eduardo Rossini Ribeiro, ${ }^{1}$ Lucas Camargo Scudeler, ${ }^{1}$ Marcos Frozoni, ${ }^{1}$ Maíra Prado, ${ }^{2}$ Adriana De-Jesus-Soares ${ }^{1}$ ${ }^{1}$ Mestrado em Endodontia, Centro de Pesquisas Odontológicas São Leopoldo Mandic, Campinas, SP, Brasil

${ }^{2}$ Faculdade de Odontologia, Universidade Veiga de Almeida, Rio de Janeiro, RJ, Brasil

- Os autores declaram que não há conflito de interesse.

\section{Resumo}

Objetivo: avaliar a prevalência das injúrias traumáticas dentárias em atletas e o conhecimento dos esportistas sobre as condutas emergenciais em casos de traumatismos dentários, assim como a frequência do uso de protetores bucais. Material e Métodos: foram avaliados 179 esportistas, com idades entre 7 e 28 anos, atletas amadores de futebol, na cidade de Campinas-SP, através da aplicação de um questionário para avaliar os conhecimentos sobre a conduta a ser tomada em caso de trauma dentário, experiência anterior e os tipos de injúrias sofridas durante a prática esportiva, relação atleta/cirurgião-dentista e uso do protetor bucal. Os esportistas foram também examinados clinicamente, avaliando presença de lesões traumáticas, tratamento realizado/sequelas, grupamento dental, número de dentes afetados, selamento labial e overjet incisal. Resultados: a média de idade encontrada foi de 14,8 anos. A maioria (72,6\%) relatou nunca ter recebido qualquer informação a respeito de trauma dentário. Em relação ao uso do protetor bucal, apenas 2,8\% relataram usar; $43 \%$ dos entrevistados não saberiam como proceder em um caso de avulsão dentária. Conclusão: a prevalência de trauma dentário verificado durante o exame clínico na população estudada foi de $12,7 \%$. $\mathrm{O}$ conhecimento sobre as condutas pós-trauma foram insuficientes. $\mathrm{O}$ uso dos protetores bucais entre os atletas avaliados foi baixo.

Palavras-chave: Traumatismos dentários; Esportes; Odontologia.

Abstract

Objective: to evaluate the prevalence of dental traumatic injuries in athletes and the knowledge of sportsmen about emergency procedures in cases of dental trauma, as well as the frequency of mouth guard use. Material and Methods: a total of 179 sportsmen, aged between 7 and 28 years, who were amateur soccer athletes in the city of Campinas, SP, Brazil, were evaluated by a questionnaire to assess their knowledge about appropriate conduct in cases of dental trauma, previous experience and the types of injuries suffered during their time practicing sports, athlete/dentist surgeon relationship and the use of a mouth guard. The athletes were also clinically examined, evaluating the presence of traumatic lesions, treatment that had been performed and its sequels, dental grouping and number of affected teeth, type of lip sealing and the size of the incisal overjet. Results: the mean age was 14.8 years. Most of the respondents (72.6\%) never received any information about dental trauma. Regarding the use of the mouth guard, only $2.8 \%$ reported use; $43 \%$ of the interviewees did not know how to proceed in cases of avulsion. Conclusion: the prevalence of dental trauma verified during clinical examination in the study population was $12.7 \%$. Knowledge about appropriate post-traumatic conduct was insufficient. The use of mouth guards among the evaluated athletes was low.
\end{abstract}

Keywords: Dental injuries; Sports; Dentistry.

\section{Introdução}

$\Delta$ s injúrias traumáticas dentárias nas atividades esportivas, especialmente em crianças e adultos jovens, têm sido relatadas com frequência. A intensidade e a frequência do contato durante as competições podem ser os principais determinantes da lesão dentária e a maior frequência de lesões orofaciais acontece em esportes de contato, ou seja, aqueles nos quais os esportistas interagem fisicamente, podendo haver choques ou colisões. ${ }^{1-3}$

A severidade dessas lesões traumáticas pode variar, desde uma simples fratura de esmalte, até danos mais sérios, como nos casos de intrusões e avulsões dentárias, que podem causar danos irreversíveis à polpa e ao tecido periodontal, levando à perda do elemento dental. ${ }^{4} \mathrm{~A}$ maioria dos casos de traumatismos dentários afetam os incisivos centrais superiores, devido a sua posição mais anterior e proeminente no arco dental. A associação dos fatores de risco como overjet acentuado e selamento labial inadequado, aumentam a frequência dos traumatismos na região anterior. ${ }^{4,5}$

Uma vez que os danos podem ser irreversíveis e apresentar um prognóstico duvidoso, dependendo da intensidade e do tipo, a utilização do protetor bucal pode reduzir significativamente a frequência e a gravidade das lesões orofaciais no esporte. Portanto uma proteção adequada com equipamentos de segurança pode diminuir o número e o grau de severidade destas injúrias. ${ }^{3,6-9}$

O prognóstico favorável destes casos está relacionado com medidas de pronto atendimento adequadas. O tratamento tardio ou medidas incorretas podem reduzir drasticamente o sucesso do tratamento levando, em muitos casos, à perda do elemento dentário. ${ }^{10}$

Tendo em vista os fatores de risco relacionados à ocorrência de traumatismos dentários e à ocorrência de lesões traumáticas, durante a prática esportiva, o presente estudo teve como objetivo avaliar a prevalência das injúrias traumáticas dentárias em atletas e o conhecimento dos esportistas sobre as condutas emergenciais em casos de traumatismos dentários, assim como a frequência do uso de protetores bucais.

\section{Material e Métodos}

Este estudo foi aprovado pelo Comitê de Ética em Pesquisa do Centro de Pós-Graduação São Leopoldo Mandic/Faculdade de Odontologia com o parecer de número 917.390.

\section{Seleção dos Voluntários}

Jogadores amadores, do sexo masculino, de escolas de fu- 
tebol da cidade de Campinas-SP, foram convidados a participar da presente pesquisa. Conforme a Resolução 196/96 do Conselho Nacional de Saúde sobre Ética em Pesquisa envolvendo seres humanos os voluntários convidados a participar da pesquisa receberam o termo de consentimento livre e esclarecido, pelo qual os participantes foram informados da importância da pesquisa, como seria realizado o exame clínico e a aplicação do questionário, assim como os riscos e os benefícios para os examinados e a privacidade das informações. Havendo o consentimento, o questionário foi respondido e, então, foi realizado o exame clínico nos esportistas para verificar a prevalência e fatores relacionados ao trauma dental e o uso de protetores bucais.

\section{Avaliação do Conhecimento sobre Trauma Dentário}

Um questionário com perguntas objetivas, escrito em língua portuguesa, e de fácil compreensão foi entregue aos participantes da pesquisa (Quadro 1). Informações pessoais como nome, idade, data de nascimento, escolaridade, local da prática esportiva foram inicialmente abordadas. Em seguida, o questionário foi composto por questões que avaliavam a conduta e o conhecimento dos atletas das medidas a serem tomadas em caso de trauma dentário, sua experiência anterior e os tipos de injúrias sofridas durante a prática esportiva e a presença do cirurgião-dentista nos centros da prática esportiva. Por fim, os atletas responderam sobre o uso do protetor bucal.

Quadro 1. Descrição do questionário

\begin{tabular}{|l|}
\hline \multicolumn{1}{|c|}{ Idade: Jogador } \\
\hline Time: \\
\hline Posição no jogo: \\
\hline 1. Formação: ( ) Ensino Fundamental ( ) Ensino Médio ( ) Graduação em andamento ( ) Nível Superior Completo ( ) Pós-graduação \\
\hline 2. Você alguma vez já recebeu informações (palestras, cursos) sobre traumatismo dentário? ( )Sim ( )Não \\
\hline 3. Quantas sessões de treinamento você faz por semana? ( )1 ( )2 ( )3 ( )4 ( )5 \\
\hline 4. Você considera importante receber informações sobre traumatismo dentário e protetor bucal? \\
( ) Muito importante ( ) Importante ( ) Indiferente ( ) Pouco importante ( ) Desnecessário \\
\hline 5. O clube (escola) no qual você joga tem dentista? ( ) Sim ( ) Não ( ) Não Sei \\
\hline 6. Acha importante ter um dentista no clube ou serviço especializado para procurar em caso de trauma dentário? \\
( ) Sim ( ) Não ( ) Não sei \\
\hline 7. Você já sofreu um traumatismo orofacial (cabeça-face-boca) durante a prática do esporte? \\
( ) cabeça ( ) face ( ) face/cabeça ( ) boca ( ) boca/face ( ) Não \\
Se o trauma foi na boca, o que aconteceu? \\
( ) Sangramento na gengiva \\
( ) Fratura dentária \\
( ) Deslocamento do dente \\
( ) Corte no lábio, gengiva, bochecha ou língua \\
( ) Amolecimento do dente \\
( ) Perdas dentais \\
\hline
\end{tabular}

8. Se você sofrer uma pancada no rosto durante a prática esportiva, o que você faz primeiro?

( ) Fala com seu treinador ( ) Encaminha-se a um centro de saúde

( ) Encaminha-se a enfermaria ( ) Procura um dentista particular

( ) Procura um serviço especializado ( ) Outro

9. Você usa protetor bucal? ( ) Sim ( ) Não

Se respondeu, sim, quando você usa o seu protetor?

( ) Durante as partidas e treinos ( ) Durante as partidas ( ) Durante os treinos

10. Você já usou um protetor bucal? ( )Sim ( )Não

Se você respondeu sim, você tem queixas enquanto usa o protetor bucal?

( )Fala ( )Respiração ( )Boca seca ( )Mau gosto e odor ( ) Náusea ( ) Outros

11. Você acha importante o uso do protetor bucal na sua prática esportiva? ( )Sim ( )Não

12. Numa dividida de bola, o atacante bate com o cotovelo na boca do zagueiro e um dente da frente sai inteiro do seu local de origem, devido ao trauma (avulsão), e cai no chão. Qual é a sua opinião?

( ) Esse dente não terá nenhuma utilidade para o tratamento.

( ) O dente não deve ser recolocado no seu lugar.

( ) O dente deve ser recolocado imediatamente.

( ) Não sei.

13. Após a cobrança de um escanteio, o goleiro é empurrado pelo atacante adversário e bate com a boca na trave, quebrando uma parte do dente da frente, perdendo-se apenas a parte visível do dente. Qual é a sua opinião?

( ) Não há nenhuma utilidade a parte quebrada do dente.

( ) O pedaço quebrado do dente não deve ser recolocado no seu lugar.

( ) O pedaço do dente deve ser guardado para depois ser recolocado.

( ) Não sei. 


\section{Avaliação Clínica dos Atletas}

A avaliação clínica foi realizada nas escolas onde os esportistas foram examinados através de exame clínico simples, com iluminação natural, por examinadores previamente calibrados, sem necessidade de equipamento odontológico, teste de sensibilidade pulpar ou exames radiográficos. Apenas os incisivos superiores e inferiores foram avaliados, sendo escolhidos por serem os dentes mais susceptíveis aos traumatismos. Foi utilizada cadeira comum para os atletas e os cuidados necessários em relação às normas de biossegurança foram tomados, através do uso de equipamentos de proteção individual (avental, gorro, máscara, óculos de proteção e luvas descartáveis).

Entre os atletas foi avaliado a prevalência das lesões traumáticas, tratamento realizado e suas sequelas, grupo dental e número de dentes afetados. A avaliação da presença de traumatismo dentário foi baseada na classificação proposta por O’Brien modificada por Cortes. ${ }^{10}$ Também foi avaliado o selamento labial e tamanho do overjet incisal. ${ }^{11}$

Para o exame dos atletas, foram utilizados espelhos clínicos, espátulas descartáveis de madeira de ponta reta e gaze estéril. O material foi levado em quantidade suficiente para cada dia de trabalho nos diferentes clubes.

Para a medição do overjet incisal, o atleta foi posicionado em máxima intercuspidação e a medida determinada a partir da distância da face vestibular do incisivo inferior à face incisal do incisivo superior, através do auxílio de uma espátula de madeira de ponta reta, cuja sinalização foi realizada por um grafite (Figura 1). Para impedir a infecção cruzada durante as medições, a ponta do grafite foi mantida com um comprimento de 10 milímetros e após a sinalização, esta ponta foi quebrada sobre a espátula de madeira. As espátulas, contendo a identificação de cada atleta, foram separadas individualmente em sacos descartáveis e por clube. Para facilitar a visualização das marcações nas espátulas, utilizou-se uma régua para ampliar a anotação do grafite em toda a extensão da mesma, confeccionando, logo após uma pequena canaleta, com auxilio de um estilete, sobre a medida, para facilitar a colocação do paquímetro digital, aumentando a precisão na leitura. As medidas foram realizadas em laboratório, sobre bancada iluminada para melhor visualização das referências. ${ }^{12}$ Os valores superiores a três milímetros foram considerados como overjet incisal aumentado.

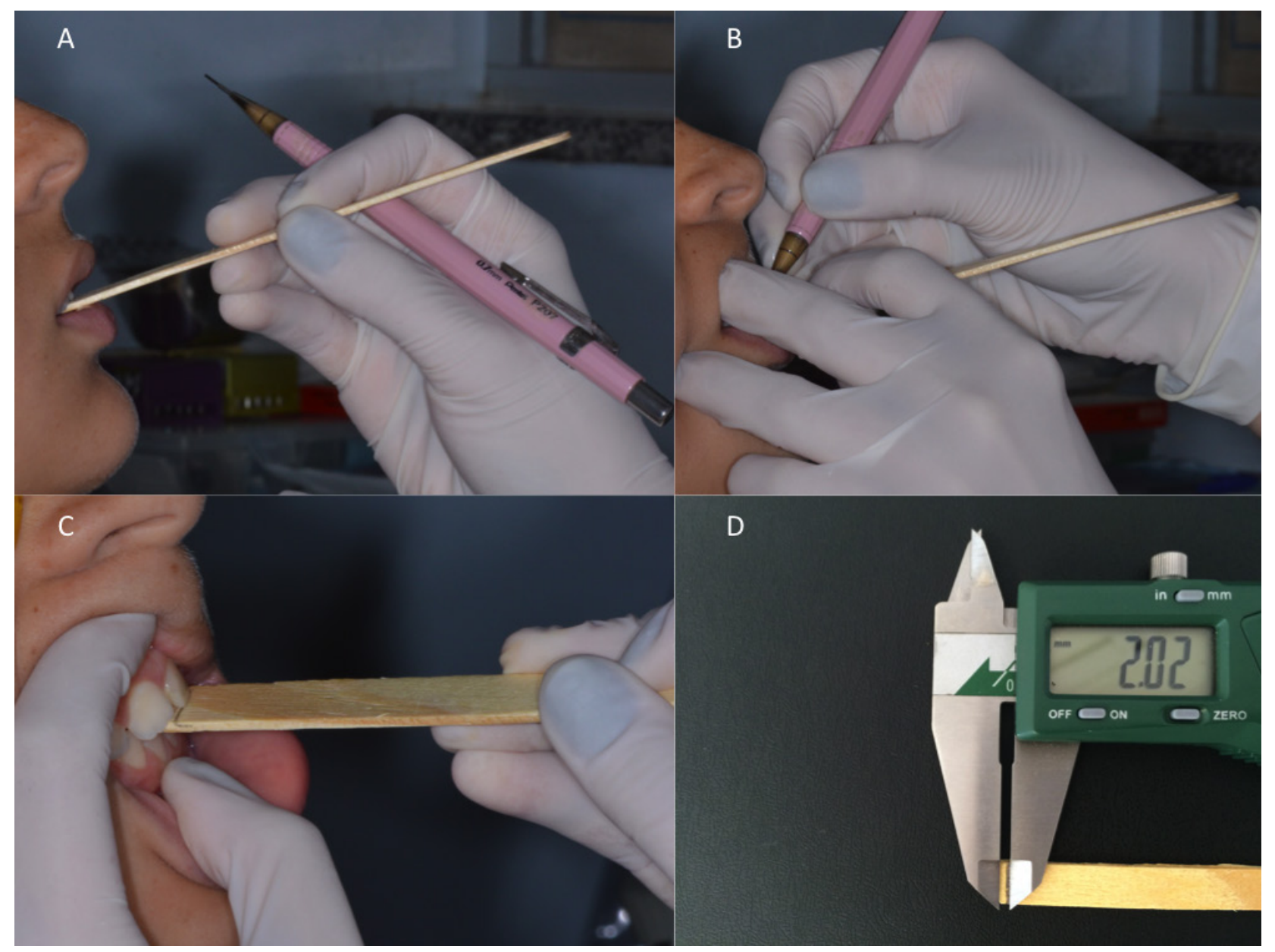

Figura 1. Marcação do overjet incisal (A-C) e mensuração com paquímetro digital (D) 
Para a verificação do selamento labial, o esportista leu um texto mentalmente para que o examinador pudesse observar a posição de seus lábios sem que o mesmo percebesse. ${ }^{13}$ A proteção foi considerada adequada, se o lábio cobrisse os incisivos superiores em posição de repouso, caso contrário, foi considerada inadequada.

Os esportistas que foram diagnosticados ao exame clínico com algum tipo de traumatismo dentário, foram entrevistados com perguntas específicas para investigar sobre a história passada do trauma dental, frequência da prática esportiva, uso de protetor bucal no momento do acidente, local em que ocorreu o acidente, etiologia e idade no momento do acidente.

\section{Análise de Dados}

Para avaliação dos questionários e das fichas dos exames clínicos os dados foram tabulados em planilha do Microsoft Excel 2010 e a análise descritiva dos mesmos foi calculada por meio da frequência e porcentagem. As possíveis correlações existentes foram avaliadas utilizando o teste de Quiquadrado, adotando um $p=0,05$.

\section{Questionário}

\section{Resultados}

\section{Análise Descritiva da População Avaliada}

A amostra desta pesquisa foi composta por 179 esportistas. Quanto à origem dos atletas, $85(47,5 \%)$ eram jogadores da Escola Chute Inicial Corinthians, 94 (52,5\%) eram jogadores da Escola de futebol Bate Fácil.

Os esportistas avaliados apresentavam entre 7 e 28 anos, com idade média de 14,8 e mediana de 14 anos. A distribuição da faixa etária é mostrada na Figura 2.

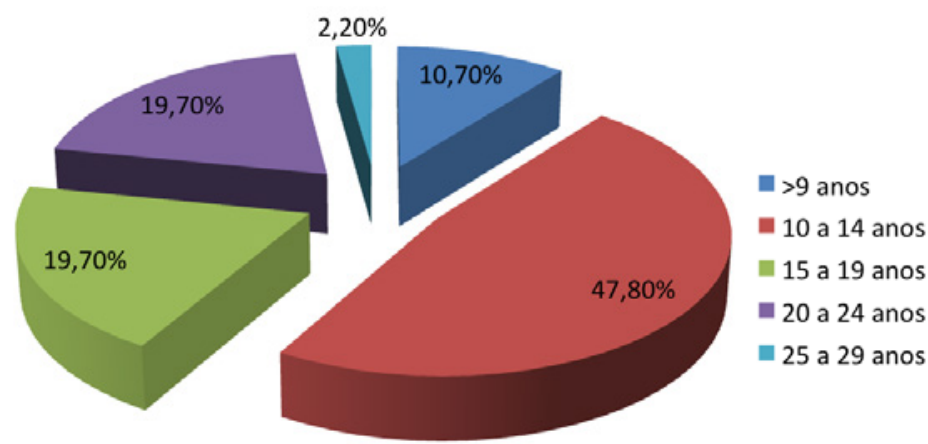

Figura 2. Frequência relativa da distribuição por idade

Quanto ao tempo de realização da prática esportiva, 48 atletas $(26,8 \%)$ realizavam a atividade há menos de 3 anos, $49(27,4 \%)$ entre 3 a 5 anos, $20(11,2 \%)$ entre 6 a 9 anos e 32 $(17,9 \%)$ praticavam o esporte há mais de 10 anos. Vinte pessoas $(11,2 \%)$ não responderam à pergunta.

A maior frequência de treino observado foi de duas vezes por semana com $54,2 \%$, seguido dos esportistas que praticavam três vezes por semana $(23,6 \%)$, uma vez por semana
$(9,5 \%)$, quatro vezes por semana $(6,7 \%)$ e mais de cinco vezes por semana $(1,7 \%)$.

Em relação ao grau de escolaridade, 54,7\% (98 indivíduos) cursavam o ensino fundamental, $20,7 \%$ (37) o ensino médio, 21,2\% (38) graduação em ensino superior e 3,4\% (6) apresentavam nível superior completo.

Conhecimento e Conduta dos Atletas em Relação ao Traumatismo Dentário e Experiência Anterior em Relação às Injúrias Sofridas Durante a Prática Esportiva e a Presença do Dentista nos Centros de Treinamento

Em relação à frequência com a qual os atletas receberam algum tipo de orientação (palestra ou curso) sobre traumatismo dental, 72,6\% (130) responderam que nunca receberam esse tipo de orientação e apenas $24 \%$ (43) já receberam algum tipo de orientação sobre o trauma dental. Seis atletas $(3,4 \%)$ não responderam a essa questão.

Dos 179 entrevistados, 54 (30,2\%) relataram ser muito importante receber informações sobre o traumatismo dental, $84(46,9 \%)$ relataram ser importante, $24(13,4 \%)$ consideraram indiferente, $9(5 \%)$ consideraram pouco importante, $3(1,7 \%)$ consideraram desnecessário e $1(0,6 \%)$ não respondeu.

Em relação à conduta a ser tomada frente ao trauma na face, 135 relatariam ao treinador, 13 procurariam um centro de saúde, 10 a enfermaria, 8 um serviço especializado, 6 um dentista particular, 4 tomariam outra conduta e 3 não responderam (Figura 3).

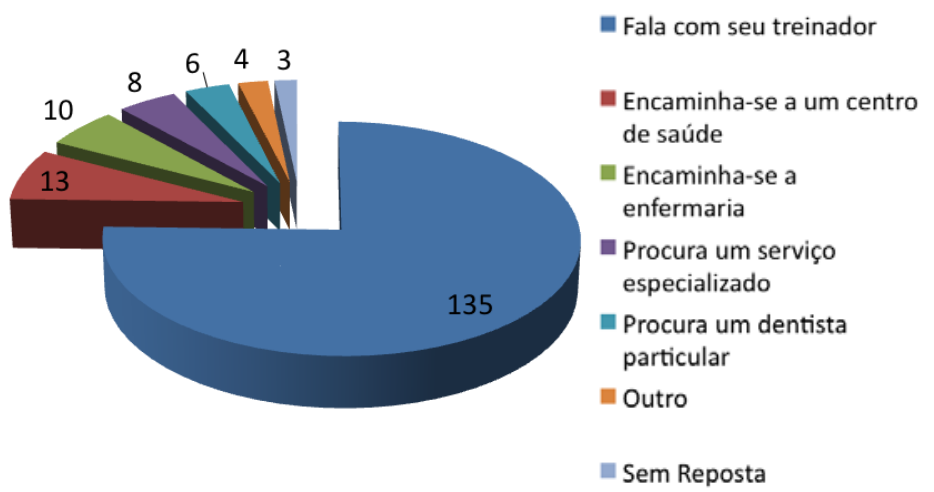

Figura 3. Frequência absoluta ( $\mathrm{n}$ ) das condutas em caso de trauma na face durante a prática esportiva

A maioria dos entrevistados $(72,7 \%)$ nunca sofreu traumatismo orofacial (cabeça-face-boca). Àqueles que relataram a ocorrência de trauma, 21 casos $(11,73 \%)$ foram na boca e $11(6,15 \%)$ na cabeça.

Com relação às lesões bucais, as duas mais frequentes foram o sangramento gengival $(28,95 \%)$ e corte no lábio, gengiva, bochecha ou língua $(28,95 \%)$, conforme apresentado na tabela 1.

Rev. Bras. Odontol., Rio de Janeiro, v. 74, n. 2, p. 88-95, abr./jun. 2017 
Tabela 1. Frequência absoluta (n) e relativa (\%) do tipo de traumatismo bucal

\begin{tabular}{l|c|c}
\hline \multicolumn{1}{c|}{ Tipo de injúria traumática } & N & $\%$ \\
\hline Sangramento gengival. & 11 & 28,95 \\
\hline Corte no lábio, gengiva, bochecha ou língua. & 11 & 28,95 \\
\hline Fratura dentária. & 4 & 10,53 \\
\hline Sangramento gengival/Fratura dentária. & 3 & 7,89 \\
\hline $\begin{array}{l}\text { Fratura dentária/Corte no lábio, gengiva, bo- } \\
\text { checha ou língua. }\end{array}$ & 3 & 7,89 \\
\hline $\begin{array}{l}\text { Perdas dentárias. } \\
\text { Deslocamento dentário. }\end{array}$ & 2 & 5,26 \\
\hline $\begin{array}{l}\text { Sangramento gengival/Fratura dentária/Corte } \\
\text { no lábio, gengiva, bochecha ou língua. }\end{array}$ & 1 & 2,63 \\
\hline $\begin{array}{l}\text { Sangramento gengival/Corte no lábio, gengi- } \\
\text { va, bochecha ou língua. }\end{array}$ & 1 & 2,63 \\
\hline $\begin{array}{l}\text { Corte no lábio, gengiva, bochecha ou língua/ } \\
\text { Perdas dentárias. }\end{array}$ & 1 & 2,63 \\
\hline \begin{tabular}{l} 
Mobilidade dental. \\
\hline
\end{tabular} & 0 & 0,00 \\
\hline
\end{tabular}

Ao serem questionados sobre como proceder se ocorrer uma avulsão dental devido a um trauma durante a prática do esporte, 77 (43\%) não sabem como proceder, 59 (33\%) recolocariam o dente no lugar, $27(15,1 \%)$ não recolocaria o dente, 14 (7,8\%) não acredita que o dente tenha utilidade para o tratamento e $2(1,1 \%)$ não responderam.

O mesmo foi questionado caso ocorresse uma fratura na coroa do dente e $81(45,3 \%)$ guardariam o pedaço do dente, $63(5,2 \%)$ não sabem responder, $18(10,1 \%)$, não acham que o fragmento deverá ser recolocado e 17 (9,5\%) não acreditam na utilidade do fragmento.

Outro fator analisado foi a presença de dentista nos centro esportivos avaliados. Ao todo 143 (79,9\%) participantes relataram que não existe a presença do profissional e apenas 10 atletas $(5,6 \%)$ responderam que o clube apresenta o serviço do cirurgião-dentista. Este dado denota que mesmo havendo o serviço no centro esportivo, nem todos os integrantes sabem da existência do mesmo. Em relação à importância do dentista nos clubes, 124 (69,3\%) dos esportistas acreditam ser importante a presença desse profissional e $27(15,1 \%)$ não acham importante a presença do dentista.

\section{Uso do Protetor Bucal}

Dos 179 entrevistados, 173 (96,6\%) não utilizam protetor bucal e apenas $5(2,8 \%)$ fazem o uso. Dos esportistas que utilizam o protetor, 3 (60\%) utilizam tanto nas partidas quanto nos treinos, 1 (20\%) utiliza nas partidas e 1 (20\%) utiliza nos treinos.

Também foi perguntado se já fez o uso de protetor bucal e verificou-se que $27(15,1 \%)$ já haviam utilizado e 149
$(83,2 \%)$ nunca utilizaram. Ainda, 3 atletas $(1,7 \%)$ não responderam.

Ao serem perguntados sobre as principais queixas dos esportistas que utilizaram protetor bucal, verificou-se que $7(25,9 \%)$ relataram dificuldades na fala, $1(3,7 \%)$ tanto na fala quanto na respiração, $4(14,8 \%)$ na respiração, 3 $(11,1 \%)$ relataram a boca seca, $4(11,1 \%)$ outras queixas e alguns associaram várias queixas (Figura 4).

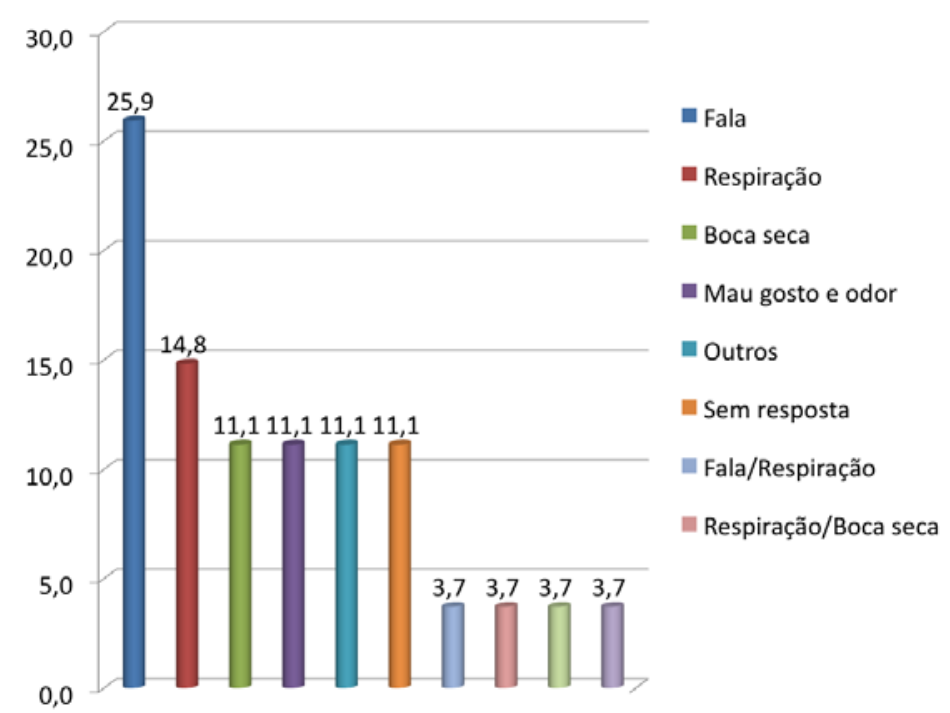

Figura 4. Frequência relativa (\%) das queixas principais dos esportistas que utilizaram protetor bucal

Apesar da baixa porcentagem de uso de protetor, $54,2 \%$ (97) relataram ser importante usar, já 43\% (77) não consideram importante o uso e $2,8 \%$ (5) não responderam.

\section{Exame Clínico}

No exame clínico, verificou-se que 158 (87,3\%) não apresentaram sinais de traumatismo e $23(12,7 \%)$ o apresentaram.

Quarenta e dois esportistas (26,3\%) apresentaram um overjet maior de $3 \mathrm{~mm}$ e $118(73,8 \%)$ um overjet menor que $3 \mathrm{~mm}$. Todos os examinados apresentaram um selamento labial adequado.

Quanto à necessidade de tratamento odontológico, $98,9 \%$ (179) não precisavam do serviço e apenas 1,1\% (2) necessitavam de tratamento relacionado ao traumatismo sofrido.

Quanto ao tipo do trauma e os dentes envolvidos, verificou-se que os tipos mais observados foram fratura coronária e reconstrução devido a trauma anterior (tabela 2).

Trinta dentes, em 23 esportistas, apresentavam sinais de traumatismos, sendo os incisivos centrais superiores os mais afetados (86,7\%), seguidos pelos incisivos laterais superiores (10\%) e incisivos centrais inferiores $(3,3 \%)$. 
Tabela 2. Critérios de classificação, descrição do tipo do trauma, dentes envolvidos, frequência e porcentagem dos dentes envolvidos no trauma

\begin{tabular}{|c|c|c|c|c|}
\hline Critério & Descrição & $\begin{array}{c}\text { Dentes } \\
\text { envolvidos }\end{array}$ & Frequência & Porcentagem \\
\hline 1- Mudança de coloração & & - & 0 & 0 \\
\hline \multirow{3}{*}{ 2- Fratura coronária } & \multirow{3}{*}{$\begin{array}{l}\text { Fratura envolvendo esmalte; esmalte e } \\
\text { dentina; esmalte, dentina e polpa; }\end{array}$} & 11 & 3 & 1,7 \\
\hline & & 21 & 2 & 1,1 \\
\hline & & 11 e 21 & 3 & 1,7 \\
\hline $\begin{array}{l}\text { 3- Ausência devido a } \\
\text { trauma. }\end{array}$ & Ausência devido a trauma. & - & 0 & 0 \\
\hline \multirow{7}{*}{$\begin{array}{l}\text { 4- Reconstrução devido a } \\
\text { trauma anterior }\end{array}$} & \multirow{7}{*}{$\begin{array}{l}\text { Restauração com resina composta. } \\
\text { Recolocação permanente com coroa, } \\
\text { aparelho móvel ou ponte, implante. }\end{array}$} & 11 & 4 & 2,2 \\
\hline & & 21 & 4 & 2,2 \\
\hline & & 12 & 1 & 0,6 \\
\hline & & 31 & 1 & 0,6 \\
\hline & & 11 e 21 & 2 & 1,1 \\
\hline & & 11 e 12 & 1 & 0,6 \\
\hline & & 21 e 22 & 1 & 0,6 \\
\hline Sem Trauma & Ausência de lesão & & 158 & 87,3 \\
\hline \multicolumn{3}{|c|}{ Total } & 181 & 100 \\
\hline
\end{tabular}

\section{Correlações}

Em relação às correlações avaliadas, não houve associação entre a posição no jogo com a presença de traumatismo $(\mathrm{p}=0,983)$. Também não foi verificada associação entre a presença do trauma com o uso atual $(\mathrm{p}=0,783)$ ou o uso anterior $(p=0,539)$ do protetor bucal. O tempo de atividade física não influenciou na presença de trauma $(p=0,42)$.

A idade foi um fator que apresentou associação com o traumatismo, sendo estatisticamente significante $(p=0,04)$. Os atletas menores até 14 anos apresentaram uma maior porcentagem de trauma, totalizando $56,5 \%$, quando comparado com os demais. Dos atletas com presença de trauma $26,1 \%$ são menores de 9 anos e 30,4\% estão entre 10 a 14 anos (tabela 3).

Tabela 3. Frequência absoluta (n) e relativa (\%) da ocorrência de traumatismo dentário em função da faixa etária dos atletas

\begin{tabular}{l|c|c|c|c|c|c}
\hline \multirow{2}{*}{$\begin{array}{c}\text { Traumatis- } \\
\text { mo }\end{array}$} & \multicolumn{6}{|c}{ Idade - n(\%) } \\
\cline { 2 - 7 } & Menor 9 & 10 a 14 & 15 a 19 & 20 a 24 & 25 a 29 & $\begin{array}{c}\text { sem } \\
\text { reposta }\end{array}$ \\
\hline Não & $13(8,3)$ & $78(50)$ & $29(18,6)$ & $32(20,5)$ & $3(1,9)$ & $1(0,6)$ \\
\hline Sim & $6(26,1)$ & $7(30,4)$ & $6(26,1)$ & $3(13)$ & $1(4,3)$ & $0(0)$ \\
\hline
\end{tabular}

Nota: Correlação significativa encontra-se em negrito (teste de Quiquadrado, $p=0,04$ )

Outro fator que mostrou diferença estatisticamente significativa foi a presença de trauma com o recebimento de informação prévia sobre traumatismo dentário. Dos 23 que apresentaram trauma dental, $13(56,5 \%)$ não receberam informações (palestras, cursos) sobre traumatismo dentário contra $7(30,4 \%)$ que receberam.

Houve associação da presença de trauma com a região de ocorrência do mesmo $(p=0,002)$. Dos 23 (100\%) esportistas que tiveram fratura dental, $6(26,1 \%)$ apresentaram lesões em boca, 5 (21,7\%) lesões em boca e face. Se compararmos com os esportistas que já apresentaram alguma lesão, mas sem fratura dental, $9 \%$ foi em boca e 3,2\% em boca e face, conforme demonstrado na tabela 4 .

Tabela 4. Frequência absoluta (n) e relativa (\%) da região da ocorrência do traumatismo em função da presença de trauma

\begin{tabular}{l|c|c}
\hline \multirow{2}{*}{ Região } & \multicolumn{2}{|c}{ Trauma dental - n(\%) } \\
\cline { 2 - 3 } & Sem Trauma & Com trauma \\
\hline Cabeça & $9(5,8)$ & $1(4,3)$ \\
\hline cabeça/boca / face & $2(1,3)$ & $0(0)$ \\
\hline cabeça/boca & $1(0,6)$ & $0(0)$ \\
\hline Face & $2(1,3)$ & $0(0)$ \\
\hline face/cabeça & $2(1,3)$ & $1(4,3)$ \\
\hline Boca & $14(9)$ & $6(26,1)$ \\
\hline boca/face & $5(3,2)$ & $5(21,7)$ \\
\hline Não & $121(77,6)$ & $10(43,5)$ \\
\hline
\end{tabular}

Nota: Associação significativa encontra-se em negrito (teste de Quiquadrado, $p=0,002$ )

\section{Discussão}

Traumatismos são muito comuns nos esportes, principalmente nas modalidades que envolvem mais velocidade e contato entre os jogadores, o que os tornam mais suscetiveis aos traumas faciais e dentais. ${ }^{14,15}$

A prevalência de trauma dentário encontrada nesta pesquisa durante o exame clínico foi de $12,7 \%$, inferior aos es- 
tudos de Levin et al., ${ }^{17}$ onde a prevalência encontrada foi de $27 \%$, de Andrade et al. ${ }^{16}$ que encontrou uma prevalência de 49,6\%. A divergência em relação aos achados de Andrade et al. ${ }^{16}$ pode estar relacionada ao fato de no presente estudo a avaliação ter incluído apenas jogadores amadores, que realizam poucos treinos por semana. A maioria dos atletas avaliados nessa pesquisa $(54,2 \%)$ treina duas vezes por semana, enquanto que apenas $1,7 \%$ realizam treinos cinco vezes ou mais na semana.

Neste estudo, $27,3 \%$ dos esportistas relataram ter sofrido algum tipo de trauma orofacial, sendo que as lesões orofaciais mais comuns foram na boca $(11,73 \%)$ e na cabeça $(6,15 \%)$. Quando as lesões aconteceram na boca, o sangramento gengival $(28,95 \%)$ foi o mais frequente. Resultados semelhantes foram encontrados por Barberini et al ${ }^{18} \mathrm{e}$ Onyeaso. ${ }^{19}$

A grande maioria dos esportistas $(72,6 \%)$ nunca recebeu qualquer informação sobre traumatismo dental. No entanto saber sobre o assunto foi considerado importante por $46,9 \%$ e muito importante por 30,2\%, demonstrando o interesse do grupo em receber essas informações. Dados semelhantes foram encontrados nos estudo de Calado et al. ${ }^{20}$ e Rodrigues et al. ${ }^{21}$

No caso de sofrer um traumatismo dentário, a primeira conduta da maioria dos participantes (135) seria procurar a ajuda do treinador, o que demonstra que a equipe que acompanha os atletas necessita de conhecimentos sobre as corretas medidas de pronto atendimento quando forem solicitados. Nos casos de avulsão dental apenas 33\% dos participantes reimplantaria o dente, enquanto que $43 \%$ não saberia o que fazer. Para as fraturas dentárias, $45,3 \%$ considera que o pedaço do dente terá alguma utilidade para o tratamento restaurador enquanto os demais participantes não souberam responder, não acham que o fragmento deverá ser recolocado ou não acreditam na utilidade do fragmento. Esses resultados demonstram que grande parte da população entrevistada não tem ciência da importância dos procedimentos de emergência apropriados nos casos de trauma dental. Infelizmente esses achados não são únicos, sendo também encontrados nos estudos de Panzarini et al. ${ }^{22} \mathrm{e}$ Mori et al. ${ }^{23}$

Em relação ao uso de protetores bucais, apenas 2,8\% doa atletas usa protetor bucal, valores reduzidos, como observado também nos estudos realizados por Levin et al., ${ }^{17}$ Sethi et al. ${ }^{24}$ e Dursun et al. ${ }^{25}$ com 4,25\%, 3\% e 2,9\% de uso, respectivamente. Dos esportistas que não usavam, 15,1\% já havia usado alguma vez e apresentava alguma queixa quanto ao uso, sendo a dificuldade na fala a principal queixa $(25,9 \%)$, assim como Sethi et al. ${ }^{24}$ com $33 \%$. Apesar da falta de uso de protetores bucais, $54,2 \%$ dos entrevistados acha importante seu uso no prática esportiva, o que indica a necessidade de aumentar o acesso dos esportistas aos protetores bucais para prevenir os traumatismos bucais.

$\mathrm{Na}$ avaliação do overjet, foi escolhida uma metodologia apoiada nos resultados encontrados em estudos que mostravam o overjet incisal acima de $3 \mathrm{~mm}$ como um fator de risco ao trauma. ${ }^{26,27}$ Nos esportistas avaliados, 26,3\% apresentaram overjet maior que $3 \mathrm{~mm}$. Nos achados desta pesquisa, não houve correlação positiva entre o trauma dental e o overjet acentuado. Estes resultados divergem de estudos prévios $^{26,27}$ e podem estar assocados a faixa acentuada de distribuição da amostra.

O dente mais afetado pelas lesões traumaticas foi o incisivo central superiore, correspondendo a $86,7 \%$ dos casos. Este resultado corrobora com estudos prévios. ${ }^{1,16}$

Não foi encontrada associação entre a posição no jogo com a ocorrência de trauma, divergindo dos achados de Correa et al., ${ }^{14}$ que relataram a posição de atacante, no futebol, como a posição mais frequentemente afetada por traumatismos.

Os traumatismos dentários têm características cumulativas em relação à idade. Neste estudo encontrou-se 82,6\% dos traumatismos dentários na faixa etária de 9 até 19 anos, corroborando com Soriano et al. ${ }^{5}$

Embora no presente estudo tenha havido a preocupação em se realizar uma validação dos questionários com atletas previamente a execução da pesquisa, uma explicação do pesquisador para os participantes em relação à realização do questionário e ainda a presença de uma pessoa durante o teste para o esclarecimento de dúvidas, alguns de voluntários não responderam algumas perguntas. Por se tratar de um questionário voluntário, os participantes não foram obrigados a retornar e responder todas as perguntas. Os autores entendem que este fato pode estar relacionado ao fato do questionário ter sido aplicado antes do treinamento e alguns voluntários por quererem iniciar o treinamento não responderam a todas as questões.

\section{Conclusão}

De acordo com os dados obtidos nos questionários e exame clínico, concluiu-se que:

a) A prevalência das injúrias traumáticas dentárias em esportistas amadores, jogadores de futebol, na cidade de Campinas-SP, foi de $12,7 \%$.

b) A maioria dos esportistas, independentemente da idade e grau de instrução, apresentou um conhecimento insuficiente sobre a conduta emergencial em casos de traumatismos dentários.

c) A frequência de uso dos protetores bucais foi considerada baixa entre os esportistas $(2,8 \%)$. 


\section{Agradecimentos}

Os autores agradecem ao professor Julio Vargas Neto pelo desenvolvimento da metodologia da medição de tamanho do overjet (trespasse horizontal).

\section{Referências}

1. Nonoyama T, Shimazaki Y, Nakagaki H, Tsuge S. Descriptive study of dental injury incurred by junior high school and high school students during participation in school sports clubs. Int Dent J. 2016;66(6):356-65.

2. Collins CL, McKenzie LB, Ferketich AK, Andridge R, Xiang H, Comstock RD. Dental injuries sustained by high school athletes in the United States, from 2008/2009 through 2013/2014 academic years. Dent Traumatol. 2016;32(2):121-7. 3. Tiryaki M, Saygi G, Ozel Yildiz S, Yildirim Z, Erdemir U, Yucel T. Prevalence of dental injuries and awareness regarding mouthguards among basketball players and coaches. J Sports Med Phys Fitness. 2017 Impress.

4. Rashid H, Vohra F, Lillywhite GR. Restorative rehabilitation in a patient with sports trauma. Eur J Dent. 2016;10(4):571-8.

5. Soriano EP, Caldas Jr AF, Carvalho MVD, Amorim Filho HA. Prevalence and risk factors related to traumatic dental injuries in Brazilian schoolchildren. Dent Traumatol 2007;23(4):232-40.

6. Sepet E, Aren G, Dogan Onur O, Pinar Erdem A, Kuru S, Tolgay CG, et al. Knowledge of sports participants about dental emergency procedures and the use of mouthguards. Dent Traumatol. 2014;30(5):391-5.

7. Dursun E, Ilarslan YD, Ozgul O, Donmez G. Prevalence of dental trauma and mouthguard awareness among weekend warrior soccer players. J Oral Sci. 2015;57(3):191-4.

8. Ilia E, Metcalfe K, Heffernan M. Prevalence of dental trauma and use of mouthguards in rugby union players. Aust Dent J. 2014;59(4):473-81.

9. Santiago E, Simões R, Soares D, Pereira JA, Caldas T. Protector Bucal "Custom-Made": Indicações, Confecção e Características Essenciais. Arq Med. 2008;22(1): 25-33.

10. Côrtes MIS, Marcenes W, Sheiham A. Prevalence and correlates of traumatic injuries to the permanent teeth of school-children aged 9-14 years in Belo Horizonte, Brazil. Dent Traumatol 2001;17:22-6.

11. Paiva PCP, Paiva HN, Oliveira Filho PM, Cortes MIS. Prevalência e fatores de risco associados ao traumatismo dentário em escolares de 12 anos de idade em Montes Claros, Minas Gerais, Brazil. Ciênc. saúde coletiva [online]. 2015;20(4):1225-33.

12. Nguyen QV, Bezemer PD, Habets L, Prahl- Andersen B. A sistematic review of the relationship between overjet size and traumatic dental injuries. Eur J Orthod. 1999;21:503-15.

13. O'Mullane DM. Injured permanent incisor teeth: an epidemiological study. J Ir Dent Assoc 1972;18(4):160-73.

14. Correa MB, Schuch HS, Collares K, Torriani DD, Hallal PC, Demarco FF. Survey on the occurrence of dental trauma and preventive strategies among Bra- zilian professional soccer players. J Appl Oral Sci 2010;18:572-6.

15. Perunsky S, Lang B, Pohl Y, Filippi A. Level of Information concerning dental injuries and their prevention in Swiss basketball - a survey among players and coaches. Dent Traumatol. 2005;21:195-200.

16. Andrade RA, Evans PLS, Almeida ALS, Silva JJR, Guedes AML, Fábio Ribeiro Guedes FR, et al. Prevalence of dental trauma in Pan American Games athletes. Dent Traumatol 2010;26:248-53.

17. Levin L, Friedlander LD, Geiger SB. Dental and oral trauma and mouthguard use during sport activities in Israel. Dent Traumatol. 2003;19:237-42.

18. Barberini AF, Aun CE, Caldeira CL. Incidência de injúrias orofaciais e utilização de protetores bucais em diversos esportes de contato. Rev Odontol UNICID 2002;14(1):7-14.

19. Onyeaso CO. Secondary Athletes: A study of mouthguards. J Nat Medical Assoc. 2004;96(2):240-5.

20. Calado MV, Barbosa RG, Correia MN, Silva CHV. Avaliação do conhecimento sobre traumatismo dentário entre os estudantes de educação fisica da UPE e UFPE. Int J Dent. 2004;3(2):358-60.

21. Rodrigues HJG, Silva RPR, Bastos RS, Bastos JRM. Odontologia Esportiva: atenção dos atletas amadores aos cuidados de saúde bucal na cidade de Bauru (SP). Rev. ABO Nac. 2005;17(1):35-9.

22. Panzarini SR, Pedrini D, Brandini DA, Poi WR, Santos MF, Correa JPT, et al. Physical education undergraduates and dental trauma knowledge. Dent Traumatol 2005;21:324-8.

23. Mori GG, Janjácomo DMM, Castilho LR, Poi WR. Evaluating the knowledge of sports participants regarding dental emergency procedures. Dental Traumatol 2009; 25:305-8.

24. Sethi HS, Kaur G, Mangat SS, Gupta A, Singh I, Munjal D. Attitude toward mouthguard utilization among North Indian school children. J Int Soc Prev Comm Dent 2016;6(1):69-74.

25. Dursun E, Ilarslan YD, Ozgul O, Donmez G. Prevalence of dental trauma and mouthguard awareness among weekend warrior soccer players. J Oral Sci. 2015;57(3):191-4.

26. Belcheva AB, Indzhova KN, Stefanov RS. Risk factors for crown fractures of permanent incisors in children from Plovdiv. Folia Med (Plovdiv). 2008;50(2):506.

27. Singh G, Garg S, Damle SG, Dhindsa A, Kaur A, Singla S. A Study of Sports Related Occurrence of Traumatic Orodental Injuries and Associated Risk Factors in High School Students in North India. Asian J Sports Med 2014;5(3):e22766

\section{Mini Currículo e Contribuição dos Autores}

1. Kathya Aparecida Palatim Semencio - cirurgiã-dentista e mestre. Contribuição: aquisição dos dados, interpretação dos dados e aprovação final.

2. Eduardo Rossini Ribeiro - aluno de graduação. Contribuição: aquisição dos dados.

3. Lucas Camargo Scudeler - aluno de graduação. Contribuição: aquisição dos dados.

4. Marcos Frozoni - cirurgião-dentista e PhD. Contribuição: participação científica e intelectual efetiva para o estudo, aprovação final.

5. Maíra Prado - cirurgiã-dentista e PhD. Contribuição: preparação e redação do manuscrito.

6. Adriana De-Jesus-Soares - cirurgiã-dentista e PhD. Contribuição: concepção e delineamento, contribuição científica e intelectual efetiva para o estudo, aprovação final.

Recebido em: 11/02/2017 / Aprovado em: 27/03/2017

Autor Correspondente

Maíra Prado

E-mail:maira@metalmat.ufrj.br 